\title{
Does language analytical ability mediate the effect of written feedback on grammatical accuracy in second language writing?
}

\section{Natsuko Shintani and Rod Ellis}

\section{University of Auckland}

\begin{abstract}
Recent research has shown that written corrective feedback helps to improve learners' grammatical accuracy in new pieces of writing. However, little is known about how individual differences mediate the extent that learners benefit from feedback. This article reports a correlational study designed to examine whether one individual difference factor language analytical ability (LAA) mediated the extent to which 118 Japanese university students of English improved in their accurate use of the past hypothetical conditional and indefinite article in new writing depending on the type of feedback (direct feedback or metalinguistic explanation) and on whether they had an opportunity to revise. Three major findings emerged. First, learners with stronger LAA benefited more from both types of feedback than learners with weaker ability. Second, LAA played a larger role for those learners who had revised their original writing following the feedback. Third, the mediating effect was only evident in new writing produced shortly after the feedback with a long term effect only found in those learners who received direct feedback and only for the past hypothetical conditional. It is proposed that the extent that LAA was involved depended on the depth of processing involved in utilizing the different types of feedback.
\end{abstract}

Keywords: Language analytical ability, written feedback, revision, indefinite article, past hypothetical conditional 


\section{Introduction}

\section{Purpose of the study}

Recent research has demonstrated that feedback on the grammatical errors that second language (L2) learners make in writing can lead to improved accuracy in new pieces of writing (e.g., Author, 2013; Van Beuningen et al., 2012; Bitchener \& Ferris, 2012). However, to date, few studies have examined how individual difference factors such as language aptitude and motivation influence L2 writing (Kormos, 2012) and even fewer have investigated these factors in relation to the effect that feedback has on learners' grammatical accuracy in writing. The study reported below examines whether learner differences in one individual difference factor - language analytical ability (LAA) - mediated the extent to which adult foreign language learners manifested improvements in grammatical accuracy following different kinds of feedback on their writing.

The study is premised on the assumption that the effects of feedback are mediated by both individual difference factors and contextual factors. These influence the extent to which individual learners attend to and process different types of feedback. As a result of differing levels of engagement, learning outcomes (e.g., improved accuracy in new writing) will vary. The study examined direct corrective feedback and metalinguistic explanation and, also whether the learners were required to just pay attention to the corrections or also to revise after receiving the feedback. We selected one individual difference factor - LAA - and measured its mediating role in learning outcomes.

\section{Types of feedback}

Feedback on writing can focus on organisation, content or linguistic form. We are concerned only with linguistic feedback, which comes in various forms (see Author, 2009). It can be focused or unfocused depending on whether it is directed at just one or two linguistic errors or a broad range of errors. It can be indirect or direct depending on whether the errors are just indicated or corrections provided. Learners can also receive metalinguistic clues or explanations of their errors.

Previous studies (e.g., Bitchener, 2008; Bitchener \& Knoch, 2010) have shown that focused feedback is effective in the sense that it results in gains in grammatical accuracy in new pieces of writing and, in some cases, is more effective than unfocused feedback (Sheen et al., 2009). Both direct and indirect feedback have been found to be effective but Bitchener 
and Knoch (2010), Hashemnezhad and Mohammadnejad (2012) and Frear (2012) all reported direct to be more effective than indirect. Fewer studies have investigated feedback consisting of metalinguistic explanations of errors and they have produced mixed results. ${ }^{[1]}$ In two studies that investigated English articles, Author (2013) reported that it was more effective than direct feedback while Sheen (2007) found the metalinguistic feedback combined with direct feedback was more effective than direct feedback by itself. However, (Author, 2014) found direct feedback led to greater accuracy in the use of a complex grammatical structure (past hypothetical conditionals) than metalinguistic explanation by itself. However, the actual types of metalinguistic feedback differed in these studies. These studies motivated the decision to investigate both focused direct and metalinguistic feedback on different grammatical structures.

\section{Revision following feedback}

When learners are asked to revise their writing following feedback they have an opportunity to engage with the feedback. They can refer to the corrections they have been given or, in the case of metalinguistic explanations of their errors, can attempt to apply these to self-correcting their own errors. A number of studies (e.g., Chandler, 2003; Frear, 2012; Van Beuningen et al., 2012) have produced results that indicate that asking learners to revise immediately after they have received feedback is advantageous. However, it is also possible that feedback can be effective even if there is no opportunity to revise providing learners are required to process the corrections they have been given.

\section{Language analytical ability and feedback}

Language analytical ability is one of the abilities comprising language aptitude. Carroll's (1981) model of language aptitude includes both 'grammatical sensitivity' (i.e., the ability 'to recognize the grammatical functions of words or other linguistic entities in sentence structures'(p. 105)) and 'inductive learning ability' (i.e., the ability 'to infer or induce the rules governing a set of language materials, given sample language materials that permit such inferences' (p. 105)). However, the Modern Language Aptitude (Carroll \& Sapon, 1959) Test did not distinguish these two aspects of LAA, leading Skehan (1998) to propose they can be combined into a single component, which he labelled 'language analytical ability'. The test in the study reported below measured language analytical ability using the same kind of test as in the Pimsleur Language Aptitude Battery (Pimsleur, 1966). 
There are a number of theoretical reasons for believing that LAA is a factor in learners' ability to benefit from and make use of feedback. The construct of LAA is closely related to the construct of explicit knowledge. Author (2004) defined the latter as 'knowledge about language and about the uses to which language can be put' (p 229). Author considered LAA as 'the essential ability underlying the development of explicit knowledge' (p. 251) and cited a number of studies (e.g., Alderson et al., 1997) that have reported significant correlations between measures of language analytic ability and metalinguistic knowledge. Williams (2012) also argued that written corrective feedback contributes primarily to explicit rather than implicit knowledge. Therefore, learners with stronger LAA may gain more from the feedback and be able to make better use of it when revising their writing or in new writing.

Kormos (2012) considered the role of language aptitude in relation to Kellog's (1996) model of the writing process. This distinguishes three interactive processes: formulation (involving conceptualizing and organising content and translating this into words), execution (the creation of a handwritten or typed text) and monitoring (checking that the text expresses the writer's intention and making revisions where needed). Kormos proposed high aptitude learners were more likely to be advantaged in that part of the writing process where they had to translate ideas into linguistic units than in that part where they were conceptualizing content and making organizational decisions. She suggested that 'learners with high level of metalinguistic awareness might notice their errors more easily and might consciously devote more attention to monitoring linguistic accuracy' (p. 396). In line with this position, it can be hypothesized that learners with strong language analytic ability will pay more attention to feedback and make better use of it when revising or writing a new text. However, as pointed out below alternative positions are possible depending on the type of feedback, how much individual students need assistance, the abilities they need to draw on to process the feedback and the use they make of it in new pieces of writing.

Robinson's (2001) Aptitude Complex Hypothesis affords more precise proposals about how LAA mediates the effects of feedback. Robinson distinguished 'primary abilities' and 'second order abilities'. The primary abilities underlie the second order abilities, which are directly related to the acquisition process. Quoting Snow (1994), he proposed that the second order abilities combine into aptitude complexes that influence learning. One such complex is 'aptitude for explicit rule learning', which involves the primary abilities of grammatical sensitivity and rote memory. These feed into the second-order ability of 
metalinguistic rule rehearsal. Robinson hypothesizes that learners who are high in this ability will be better equipped to benefit from explicit explanation of linguistic features. Robinson did not apply his theory to written feedback but the theory suggests that those learners strong in LAA will benefit from metalinguistic explanation as this draws more directly on LAA. In contrast, LAA may play a lesser role in direct written corrective feedback where learners are given the corrections and thus do not have to work them out for themselves. However, LAA may play a role when learners analyse and generalize the direct written corrective feedback they received to new instances (i.e. in a new piece of writing).

Another possibility is that that metalinguistic feedback will be of greater value to learners who are weaker in LAA as they do not need to work out metalinguistic rules for themselves. Some support for this argument comes from Erlam (2005). She found that LAA was not related to gains on a written production test when the instruction involved metalinguistic rule-explanation but it was to the gains made by groups taught inductively (i.e. without any rule-explanation). However, it was also related to gains made by a structured input group that did receive rule-explanation. Erlam concluded that LAA becomes more significant when learners have to work out the grammatical rule for themselves. As Dörnyei and Skehan (2003) noted 'some people are better able to analyse material and make generalizations based on it better than others' (p. 599). This is what learners need to do when confronted with direct corrections. However, Erlam also reported that LAA was positively related to gains made by a group that received rule-explanation followed by oral structured input activities suggesting that in this condition those learners with stronger LAA were better able to process and learn from the input. Overall, then, her study points to a complex interaction between LAA and types of instruction.

Our study draws on Cronbach's (1957) proposals about aptitude-treatment interaction (ATI), which are well-documented in educational psychology (see DeKeyser, 2012; Hwu, Pan, \& Sun, 2014). ATI concerns the ways in which components of language learning aptitude interact with different L2 learning conditions (e.g., different teaching methods, different types of L2 input, different target structures). ATI, however, is neutral as to whether LAA helps learners benefit from explicit information about grammatical features or whether it becomes more important when learners need to induce explicit regularities from exemplars. Investigating these possibilities can inform how we can match the type of feedback to learners' aptitude profiles in the kind of compensatory approach recommended by Ranta $(2005)^{[2]}$. 
We have been able to locate only one such study that has investigated the relationship between LAA and the effects of written feedback on language development. Sheen (2007) investigated the effects of two types of feedback - direct feedback and direct feedback in combination with metalinguistic explanation - on adult ESL learners' gains in accurate use of the definite and indefinite article in a speeded dictation test, an error correction test and in new writing. Significant positive correlations were found between LAA and gains in accuracy in both groups. In other words those learners with higher levels of LAA benefited more from both types of feedback. However, stronger correlations were evident for the direct plus metalinguistic feedback group suggesting that LAA is of greater advantage for processing feedback involving metalinguistic explanation, thus supporting Robinson's proposal.

\section{LAA and the complexity of the grammatical target}

Finally, we consider whether the nature of the grammatical rule affects the role played by LAA in instructed language learning. To date, no study of feedback on L2 writing has investigated this. However, Robinson (1997) examined the relationship between grammatical sensitivity and the learning of an easy rule (subject-verb inversion following an adverb of movement or location) and a hard rule (pseudo clefts of location) in four instructional conditions, two of which are of particular interest here. He reported significant correlations between a measure of grammatical sensitivity and the test scores of both learners who were asked to search for the rules and those who were explicitly taught the rules. He found no difference in the strength of the correlations for the easy and hard rules. This study then suggests that LAA has a role to play irrespective of rule complexity. However, both of the rules Robinson investigated involved word order and might well be considered complex. In the study below we investigated the effects of feedback on a morphological feature (indefinite article) and a complex syntactic structure (past hypothetical conditional).

\section{The study}

We have seen that there are strong theoretical reasons and some empirical evidence for claiming that LAA plays a role in both the writing process and in learners' ability to make use of feedback. The results of Sheen's (2007) study pointed to LAA conferring a greater advantage when the feedback consists of metalinguistic information. However, Sheen combined direct and metalinguistic feedback so it was not possible to determine the role of 
LAA when the feedback consisted of just metalinguistic information. Sheen also investigated only one grammatical structure - English articles. Further research is clearly needed.

The study reported below is an extension of Author (2014). Author investigated the effects of two types of feedback (direct and metalinguistic explanation) under two conditions (+/- the opportunity to revise) on two English grammatical structures (the indefinite article and past hypothetical conditionals). Neither type of feedback had any effect in new pieces of writing on accurate use of the indefinite article under either condition. However, both types of feedback led to improved accuracy in the past hypothetical conditional with the direct feedback plus revision proving the most effective type.

In this follow-up correlational study we examine what role differences in the learners' LAA played in the effects of the feedback on accuracy in new writing. The study compared one group that received direct feedback with another that received only metalinguistic explanation. Also, as LAA may also play a role when learners revise their writing following feedback we compared groups that received feedback and then revised with those that only received the feedback (i.e., had no opportunity to revise). We also examined the mediating effect of LAA on two grammatical structures - indefinite article and past hypothetical conditionals. To this end, we addressed two research questions:

1. Is there any difference in the mediating role of LAA in L2 learners' processing of (a) direct written corrective feedback and (b) metalinguistic explanation as shown by their accurate use of two target structures in new writing?

2. Is there any difference in the mediating role of LAA on learners' processing of these two types of feedback when there is (a) an opportunity to revise versus (b) no opportunity to revise as shown by their accurate use of two target structures in new writing?

Given the lack of previous research and the theoretical uncertainty regarding the relative roles of LAA in processing feedback in these conditions, we were unable to formulate research hypotheses. The study should be seen as exploratory.

\section{Method}

\section{Participants}


A total of 118 learners in seven intact general English classes in a university in Japan participated in this study. They were first and second year university students, aged 18 to 21 , majoring in a variety of subjects: mathematics, science, music, physical education, arts, special needs education, and English. All the participants were Japanese speakers who had received at least six years of formal English instruction. These learners possessed extensive explicit knowledge of English grammar as a result of the kind of instruction they received at school but they had limited fluency in English and had had few opportunities to produce English in free writing tasks.

After obtaining informed consent, the participants in each intact class were randomly assigned to one of four treatment groups randomly assigned to one of four treatment groups and a control group whose results will not be discussed here.

\section{Design}

The independent variables were (1) type of written feedback (i.e., direct feedback versus metalinguistic explanation) and (2) opportunity to revise following feedback versus no opportunity. The mediating variable was LAA. The dependent variables were accuracy scores for the use of the (1) indefinite article and (2) past hypothetical conditional, which were derived from new pieces of writing. There were four separate groups:

Group 1: Direct Feedback, +Revision $(\mathrm{DF}+\mathrm{R})(\mathrm{N}=22)$

Group 2: Direct Feedback, -Revision (DF-R) $(\mathrm{N}=31)$

Group 3: Metalinguistic Explanation, + Revision $(\mathrm{ME}+\mathrm{R})(\mathrm{N}=28)$

Group 4: Metalinguistic Explanation, -Revision (ME-R) $(\mathrm{N}=37)$

All four groups received feedback on both grammatical structures in the same piece of writing. They participated in four sessions. In Week 1, the participants completed the first writing task (Task 1), which functioned as a pre-test. In Week 2, they received either DF or ME on the writing produced in Task 1. Immediately after receiving the feedback, Groups 1 and 3 were given 20 minutes to revise their original writing. They either looked at their corrected text or referred to a metalinguistic explanation handout while rewriting the original text. Groups 2 and 4 were given 5 minutes to study their feedback (i.e. they did not revise). All the groups then completed a new piece of writing (Task 2) in the same lesson without access to the feedback provided on their first piece of writing. This functioned as an 
immediate post-test. Two weeks later all the groups completed a third piece of writing (Task 3) which functioned as a delayed test.

\section{Target structures}

Two structures were the focus of the present study: (1) past hypothetical conditional and (2) indefinite article 'a/an' ${ }^{\text {[4] }}$.

Past hypothetical conditional. The hypothetical conditional structure expresses the hypothetical outcome of an event that did not occur in the past (e.g., "If she had studied hard, she wouldn't have failed her exam"). This constitutes a difficult structure for L2 learners (Celce-Murcia \& Larsen-Freeman, 1999). It requires knowledge of the tense-aspect system, modal auxiliaries and negation and it involves encoding hypotheticality and past time reference. Izumi et al. (1999) reported that the learners they investigated attended to hypotheticality but typically missed the aspect of past time reference. The focus of the study, however, was on the morphological formation of the verbs in the main and subordinate clauses, not on the choice of conditional pattern.

Indefinite article. The indefinite article has a number of functions in English but in this study we only examined its use to refer to some person or thing mentioned for the first time (e.g., "I saw $a$ funny looking dog today"). Studies have shown that the indefinite article is frequently late acquired (e.g., Parrish, 1987; Huebner, 1983). It is especially difficult for Japanese learners as there is no equivalent form in their L1 and it lacks salience in input. A number of recent DF studies have investigated articles (e.g., Bitchener, 2008; Bitchener \& Knoch, 2010; Sheen, 2007). However, they reported combined scores for ' $a$ ' and 'the'. We have elected to examine only the indefinite article as learners tend to overgeneralize the use of the definite article, making it difficult to determine if they have really acquired 'the'. Restricting the analysis to 'a/an' allows for more reliable scoring of the effect of feedback on acquisition

\section{Writing task materials}

Three dictogloss tasks were use in this study. Three passages were prepared: The Bachelor, A Trip Abroad, and University Majors. The lengths of the passages were 188 words, 207 words and 223 words respectively, and each included six hypothetical conditional sentences with six to nine occasions for the use of indefinite articles. We chose a dictogloss to ensure that there were sufficient occasions for the use of the two target structures. Because a dictogloss requires students to reconstruct the text they have heard, they are likely to try to 
reproduce the target features while primarily focused on meaning. If we had used a freewriting task, the participants may have failed to attempt to use the target structures.

The participants were given a task sheet consisting of instructions written in Japanese (the L1) followed by a table with blank spaces to fill in the key words from the listening text. The participants listened to the audio-recorded text twice. They were then given a writing sheet and 20 minutes to reconstruct the text individually. The participants were allowed to keep their task sheet and use the words they had written on it to help them reconstruct the text. The three tasks were counterbalanced in each of the groups at each time to ensure that any group differences in the learners' use of the target structures were not due to a task effect.

\section{Language Aptitude Battery for Japanese (LABJ)}

The LABJ (Sasaki, 1996) is the Japanese translation of Pimsleur's (1966) Language Aptitude Battery. The LABJ consists of three parts, measuring associative memory, language analytical ability, and phonemic coding ability. It has been used with university level learners in Japan in previous studies. For example Robinson (2005) used it to investigate third and fourth year Japanese university students and reported significant correlations with measures of explicit learning.

For this study, only the second part of the LABJ was used. This required the participants to infer the grammatical rules of an artificial language based on a set of words and sentences presented with their Japanese translations. It consisted of 15 multiple-choice questions. In each question a Japanese sentence was presented and the learners were asked to choose the correct translation in the artificial language from the four choices provided. One point was given for each correct answer.

The test was administered by the researcher in the students' normal classrooms one week after all the participants had completed Task 3 . All the participants completed the test within 20 minutes.

\section{Feedback}

The groups received only one feedback treatment as some studies have shown that a one-shot written corrective feedback treatment can lead to improvement in accuracy in new pieces of writing (e.g., Bitchener, 2008; Bitchener, Young, \& Cameron, 2005; Sheen, 2007). Both the direct feedback and the metalinguistic explanation were focused on just the two 
target structures (i.e., other errors were not corrected). The direct feedback consisted of crossing out incorrect words and writing in the correct or missing words. The metalinguistic explanation took the form of a handout in Japanese that provided general explanations of the use of the indefinite article and the form and meaning of the hypothetical conditional (see Author, 2014 for the ME handout). All the ME students received the same handout.

The students in Groups 1 and 3 (+ Revision) were told to use the feedback they were given to revise their texts. The students in Groups 2 and 4 (-Revision) were told to study the corrections carefully. However, when all the groups did the post-tests the students were not reminded to focus on these target features.

\section{Coding and scoring the writing tasks}

The two target structures were coded and scored separately. A detailed account of the scoring system can be found in Author (2014). We provide a brief account here.

Past hypothetical conditional. When a learner attempted a sentence including an 'if' clause corresponding to one of the hypothetical conditional sentences in the dictogloss passage, it was counted as one 'attempt'. For example, the sentence 'If he marry her, he will live in Italy" was coded as an attempt to use the hypothetical conditional because it corresponded to the sentence "If he had married her, he would have lived in Italy" in the dictogloss passage. Then for each attempt, points were awarded as shown in Table 1. There was a maximum of five points for each hypothetical conditional sentence.

[Table 1 around here]

Article. There were seven or eight noun phrases containing the indefinite article in the dictogloss passages. Accuracy was calculated using Pica's (1983) formula for target-like use which takes account of both suppliance in obligatory contexts and overuse:

$$
\frac{\text { Number of grammatical morphemes supplied accurately }}{\text { Number of obligatory contexts }+ \text { Number of overused forms }} \times 100
$$

To examine the reliability of the scoring, 80 texts (over $15 \%$ of the 510 texts) were re-scored by a second researcher. The overall agreement rate between the two scorers was $98.2 \%$ for the conditional scores and $92.8 \%$ for the article scores.

\section{Analysis}


The scores for the aptitude test (LABJ) and the three writing tasks were subjected to correlational analyses ${ }^{[5]}$. As the distribution of some variables did not meet the assumption of normality, Spearman's correlation coefficient was employed. In order to take account of the relationship between LAA and scores on Task 1 (i.e., prior to the feedback), partial correlations were calculated for Tasks 2 and 3 using Task 1 scores as the control variable ${ }^{[6]}$. We have reported one-tailed tests as the direction of the relationship between LAA and scores on the writing tasks could only be one way ${ }^{[7]}$.

\section{Results}

\section{Descriptive statistics}

Table 2 reports the descriptive statistics for the percentage accuracy scores in the three writing tasks. The results of repeated measures ANOVAs indicated that there were significant gains made by all four groups from Time 1 to Time 2 and also from Time 1 to Time 3 in the case of past hypothetical conditionals but that no significant gains or losses were evident for the indefinite article. None of the group comparisons for either structure were statistically significant. See Author (2014) for detailed statistical results.

[Table 2 around here]

Table 3 gives the descriptive statistics for the LABJ. There was limited variance in the scores of this test. All the learners scored 10 or higher. Nevertheless the analyses reported below resulted in a number of statistically significant correlations.

[Table 3 around here]

\section{Correlation analysis results}

Table 4 reports the results for the partial correlations. For the indefinite article, LAA was significantly correlated to accuracy scores for the DF/ - Revision group ( $r=.347)$ and also to accuracy scores for the ME/ + Revision group ( $r=.477)$ on task 2 . For the conditional, 
LAA was significantly related to accuracy scores for the $\mathrm{DF} /+$ Revision group $(r=.482)$ and also to the ME/-Revision group ( $r=.311$ ) but not for the DF/-Revision or the ME/+Revision groups on task 2. In other words, there were significant correlations in the DF-R and ME $+\mathrm{R}$ groups for articles and for the $\mathrm{DF}+\mathrm{R}$ and $\mathrm{ME}-\mathrm{R}$ groups for conditionals. No statistically significant correlations were found for LAA and Task 3 scores. The sizes of the correlations were all small to moderate. LAA accounted for a maximum of $23 \%$ of the variance in accuracy scores.

[Table 4 around here]

\section{Discussion}

Despite the limited variance in the LAA scores, a number of the correlations in Table 4 were statistically significant. By and large, however, these correlations were smaller than those reported in other studies that have investigated LAA under different instructional conditions. Robinson (1997), for example, reported correlations between language aptitude and scores on a grammaticality judgement test in the range of $r=0.23$ to $r=0.63$ following four types of instruction. Reasons for the smaller correlations in the current study may be the fact that the writing tasks required learners to attend to content and not exclusively to grammatical form and the relative lack of variance in the LABJ scores.

This was an exploratory study and we wish to emphasize that our interpretation of the correlational results is speculative and that different interpretations are possible. We also acknowledge a problem in interpreting the results. The correlational analyses show whether there is a relationship between LAA and gains in accuracy in new pieces of writing following feedback with or without revision. In interpreting these correlations, we cannot distinguish the role played by LAA in processing the feedback from that it played when learners applied they had learned from the feedback in new pierces of writing. Due to limitations in the length of this article, we have focused our interpretation only on the processing of the feedback.

The results reveal that the role played by LAA depended on a combination of three factors - the type of corrective feedback provided (DF or ME), whether the learners were required to revise the corrected text (+Revision/ -Revision), and the target structure (article/ hypothetical conditional). Table 5 below summarizes the significant correlations between 
LAA and accuracy of use of the indefinite article and the hypothetical conditional in Task 2. In this table we also suggest the nature of the ability required in the different feedback conditions. This Table shows that LAA functions differently depending on the target structure involved.

[Table 5 around here]

We first consider the results for the indefinite article. In the DF feedback condition, LAA was more strongly implicated when learners were not required to revise than when they were asked to revise. We suggest that when the learners revised they simply copied the corrections provided and did not need to engage in any analysis of the rule. However, when they did not revise they may have spent more time examining and analysing the corrections provided, drawing inductively on their LAA as they did so. In the ME feedback condition, however, LAA was strongly implicated when learners were required to revise as the learners needed to work out how to apply the explanation deductively to correcting their article errors. In contrast, when they did not have to revise, LAA played a lesser role as all they needed to do was to read the explanation provided. For the indefinite article, then, the relevance of LAA depended on the depth of processing demanded by the treatment conditions. The greater the depth of processing required, the more that LAA was implicated and the greater the learners' accurate subsequent use of the indefinite article in Task 2.

The pattern of results is very different for the hypothetical conditional. In the DF condition, asking learners to revise appears to have led to learners drawing more strongly on their LAA. In other words, the learners did not just copy their corrections but also attempted to work out the rule for hypothetical conditionals as they did so. Why did this happen for hypothetical conditional but not for the indefinite article? The explanation may lie in the nature of the task. This required them to revise both structures in the same text. Given that the indefinite article contributes little to the meaning of the text it is likely that the learners paid little attention to it (i.e., they just mechanically copied in the corrections). The hypothetical conditional sentences, however, were central to the meaning of the text and this structure was morphologically complex, leading the learners to pay close attention to the corrections. They may also have carried out a conscious comparison of their initial attempts at constructing these sentences and the corrections. This comparison very likely drew on their LAA and may have led to the inductive formation of rule-based knowledge which they then applied in Task 
2. LAA, however, was less strongly implicated in the DF condition when no revision was required, perhaps because it did not motivate a cognitive comparison to the same extent. In the ME feedback condition, learners were given the rule and so did not need to work it out for themselves. For this complex structure, LAA appears to have been more strongly involved when there was no opportunity to revise (i.e., in simply understanding the description of the rule) rather in the deductive application of the rule in revision. Perhaps all their processing efforts went into reproducing the text leaving little space left for conscious application of the ME.

Although the pattern of correlations for the hypothetical conditional differs markedly from that for the indefinite article, we suggest that the underlying explanation is the same. Namely, that LAA is more strongly implicated when deeper explicit processing of the feedback is involved.

The answer to both research questions, then, depends on a complex interplay between the feedback type, the revision condition and the structures involved. When there was no revision required, LAA played a stronger role for the indefinite article with DF than it did for ME. However, the converse was the case for the hypothetical conditional, ME drawing somewhat more strongly on LAA than DF. When revision was required, LAA was only weakly related to accuracy resulting from the DF condition for the indefinite article, but strongly for the hypothetical conditional. Again, the converse was found for the hypothetical conditional. In other words, the differences in the mediating role of LAA depended on the nature of the grammatical structure involved and no simple answer to either RQ1 or RQ2 is possible.

The results do not clearly point to LAA playing a stronger role in the + Revision condition than in the -Revision condition. While the two strongest correlations involved the Revision condition (article $-\mathrm{r}=.477$; conditional $-\mathrm{r}=.482$ ), accounting for $22 \%$ and $23 \%$ of the total variance in gains, other significant correlations were obtained for the - Revision condition (article $-\mathrm{r}=.347$; conditional $-\mathrm{r}=.311$ ). Clearly, LAA was implicated differently depending on whether the students revised or did not revise but only in conjunction with other factors (i.e. the type of feedback and the target structure). The clearest finding of the study is that the utility of LAA depended on a complex interaction of these factors, which conspired to affect the depth with which the feedback was processed. 
The results also show that the mediating role of LAA had largely disappeared by Task 3. None of the correlations shown in Table 4 reached the .05 significance level and most of them were very weak. In other words, LAA mediated grammatical accuracy in writing that was completed shortly after the feedback but not in writing completed two weeks later. This can be explained if it is assumed that LAA only played a role in the development and application of the learners' explicit knowledge and that the one-shot feedback was insufficient to ensure durability of this knowledge (see Author 2014). This was very clearly the case for the hypothetical conditional (see Table 2).

\section{Conclusion}

Finally, we turn to consider what light the study has shed on the theoretical issues raised in the introduction. The results do not lend clear support to the claim that that LAA will play a stronger role when the feedback is metalinguistic in nature. High LAA was found to benefit both those learners who received metalinguistic feedback and those learners who received direct feedback. It would seem, then, that LAA is a factor in both processing metalinguistic explanation deductively and direct corrections inductively and then applying what they have learned in a new piece of writing. The results lend some support to the view that LAA is more important when learners have to work out the grammatical rule for themselves. While LAA was found to be significant in both the metalinguistic explanation and direct feedback conditions, its role was stronger in the latter when revision was also required. The results differ from those reported by Sheen (2007). Sheen found that LAA correlated only weakly and non-significantly with gains scores for accurate use of English articles in writing completed shortly after the learners had received direct feedback but correlated significantly with gains scores in writing completed later. In the present study, significant correlations were only found for accuracy in the immediate writing task. However, close comparisons with Sheen's study are not possible as she investigated the effects of feedback on only one structure (articles), she used a different test of LAA, metalinguistic explanation was provided on specific errors and the participants did not revise.

The study suggests that the role played by LAA in processing feedback is complex, depending on interactions among three variables - the type of feedback, whether learners are asked to revise, and the nature of the grammatical target (e.g. whether it is semantically important for the writing task and is morphologically complex) - and that the extent to which 
LAA comes into play depends on how these variables affect the depth of processing of the feedback. We have suggested that LAA figures more strongly when the variables conspire to induce greater depth of processing of a target structure.

Vatz et al (2013) concluded the results of correlational studies are 'often complex and difficult to interpret' (p. 291) as indeed has been shown to be the case in the present correlational study. Vatz called for more rigorously designed ATI studies. The results of the present study, however, suggest that it might be difficult to design a study that could take account of the complex interaction of factors involved (e.g. type of feedback; +/-Revision; choice of target structure) and that it might be premature to try to do so. Perhaps, for the time being, further exploratory correlational studies are needed to provide a clearer picture of when and under what conditions LAA plays a role in how learners process feedback on their writing.

We acknowledge a number of limitations in this exploratory study. There was little variance in the scores of test of LAA (LABJ) that we used. Feedback was provided on only one occasion and was directed at two grammatical structures. It is possible that different results would have been obtained if the learners had received feedback on several pieces of writing and needed to attend to a single grammatical structure. The writing tasks we used, while successful in eliciting the use of the two target structures, led to writing of a contrived nature. Perhaps the major limitation is that we did not obtain any online measures of how the participants processed the feedback they received or the use that made of it in new pieces of writing. Future research is needed to address these limitations.

\section{Notes}

1. One reviewer pointed out that metalinguistic explanation might not be construed as 'feedback'. However, while it is not 'corrective feedback' it clearly does constitute 'feedback' if learners receive the explanation after they have completed the writing and are required to use it to locate and correct their own errors.

2. See Vatz et al. (2013) for a review of ATI studies in the field of SLA. The conclusion these authors reached was that "while many of the studies show that a particular aptitude is, indeed, relevant to the success of a certain type of instruction, there is not enough research on matching a treatment a priori to fit a students' aptitude profile to 
warrant any conclusion that the ATI instructional strategy would maximize learning' (p. 286).

3. Both the indefinite article and the hypothetical conditional can be considered difficult to acquire. Thus they might both be considered developmentally beyond the learners in this study. However, both structures can be learned explicitly and, indeed, both would have been explicitly taught previously to these learners. Our study was not directed at investigating whether the learners 'acquired' these two structures in Krashen's (1981) sense. It focused on whether the feedback helped learners to achieve greater accuracy in the use of the two structures in writing, which allows for the use of 'learned' (i.e., explicit) knowledge. The question of the learners' developmental readiness, therefore, is arguably not relevant.

4. We considered using ANCOVAs with language aptitude scores as the covariate. However, neither the writing nor the aptitude scores met the conditions for the use of ANCOVA. Thus, we elected to use correlation analyses, which we also felt were more appropriate for the exploratory nature of the study.

5. The values for the correlations between the LABJ and the Time 1 scores were as follows. For the article scores, the DF+R group: $r=.215, p=.169$; the DF-R: $r=.143$, $p=.222$; the ME+R: $r=.063, p=.376$; the ME-R: $r=.113, p=.252$. For the conditional scores, the DF+R: $r=-.344, p=.059$; the DF-R: $r=.229, p=.108$; the ME+R: $r=.216, p=.135$; the ME-R: $r=.222, p=.093$.

6. LAA is generally considered highly stable. While learning experiences may have some effect on it over the long-term, the completion of just three writing tasks cannot reasonably be expected to have any impact.

\section{References}

Author (2004).

Author (2009).

Author (2013).

Author (2014). 
Alderson, J.C., Steel, D. and Clapham, C. (1997) Metalinguistic knowledge, language aptitude and language proficiency. Language Teaching Research, 1, 93-121. doi: $10.1177 / 136216889700100202$.

Bitchener, J. (2008). Evidence in support of written corrective feedback. Journal of Second Language Writing, 17, 69-124. doi:10.1016/j.jslw.2007.11.004

Bitchener, J., \& Ferris, D. (2012). Written corrective feedback in second language acquisition and writing. London: Routledge.

Bitchener, J. \& Knoch, U. (2010). The contribution of written corrective feedback to language development: A ten month investigation. Applied Linguistics, 31, 193-214. doi: 10.1093/applin/amp016.

Bitchener, J., Young, S., \& Cameron, D. (2005). The effect of different types of corrective feedback on ESL student writing. Journal of Second Language Writing, 14, 191-205. doi.org/10.1016/j.jslw.2005.08.001

Carroll, J. B. (1981). Twenty-five years of research in foreign language aptitude. In K. Diller (Ed.), Individual differences and universals in language learning aptitude (pp. 83118). Rowley, MA: Newbury House.

Celce-Murcia, M., \& Larsen-Freeman, D. (1999). The grammar book. New York: Heinle \& Heinle Publishers.

Chandler, J. (2003). The efficacy of various kinds of error feedback for improvement in the accuracy and fluency of L2 student writing. Journal of Second Language Writing, 12, 267-296. doi:10.1016/S1060-3743(03)00038-9

Cronbach, L. J. (1957). The two disciplines of scientific psychology. American Psychologist, $12,671-684$.

DeKeyser, R. (2012). Interactions between individual differences, treatments, and structures in SLA. Language Learning, 62 (suppl.2), 189-200.

Dörnyei, Z., \& Skehan, P. (2003). Individual differences in second language learning. In C. Doughty \& M. Long (Eds.), The handbook of second language acquisition (pp. 589630). Oxford, England: Blackwell.

Erlam, R. (2005). Language aptitude and its relationship to instructional effectiveness in second language acquisition. Language Teaching Research, 9(2), 147-171. doi: 10.1191/13621688051r161oa.

Frear, D. (2012). The effect of written corrective feedback and revision on intermediate Chinese learners' acquisition of English (Unpublished doctoral dissertation). The University of Auckland, New Zealand. 
Hashemnezhad, H. \& Mohammadnejad, S. (2012). A case for direct and indirect feedback: The other side of coin. English Language Teaching Journal, 5, 230-239. Retrieved from http://www.ccsenet.org/journal/index.php/elt/article/view/15283

Huebner, T. (1983). A longitudinal analysis of acquisition of English. Ann Arbor: Korama press.

Hwu, F., Pan, W., \& Sun, S. (2014). Aptitude-treatment interaction effects on explicit rule learning: A latent growth curve analysis. Langauge Teachintg Research 18(3), 294319. doi:10.1177/1362168813510381.

Izumi, S., Bigelow, M., Fujiwara, M., \& Fearnow, S. (1999). Testing the output hypothesis: Effects of output on noticing and second language acquisition. Studies in Second Language Acquisition, 21, 421-452. Retrieved from http://journals.cambridge.org/article_S0272263199003034

Kellogg, R. T. (1996). A model of working memory in writing. In C. M. Levy \& S. Ransdell (Eds.), The science of writing: Theories, methods, individual differences and applications (pp. 57-71). Mahwah, NJ: Lawrence Erlbaum.

Krashen, S. (1981). Second Language Acquisition and Second Language Learning. Oxford: Pergamon.

Kormos, J. (2012). The role of individual differences in L2 writing. Journal of Second Langauge Writing, 21, 390-403. doi: 10.1016/j.jslw.2012.09.003

Parrish, B. (1987). A new look at methodologies in the study of article acquisition for learners of ESL. Language Learning, 37, 361-383. doi: 10.1111/j.14671770.1987.tb00576.x

Pica, T. (1983). Methods of mropheme quantification: The effect of the interpretation of second language data. Studies in Second Language Acquisition,6, 69-78.

Pimsleur, P. (1966). The Pimsleur language aptitude battery. New York: Harcourt, Brace, Jovanovic.

Ranta, L. (2005). Language analytic ability and oral production in a second language: Is there a connection? In A. Haousen \& M. Pierrard (eds.), Investigations in instructed second language acquisition (pp. 99-130). Berlin: Mouton de Gruyter.

Robinson, P. (1997). Individual differences and the fundamental similarity of implicit and explicit adult second language learning. Language Learning 47, 45-99

Robinson, P. (2001). Individual differences. Cognitive abilities aptitude complexes and learning conditions in second language acquisition. Second Language Research, 17, 368-392. doi: 10.1177/026765830101700405 
Robinson, P. (2005). Cognitive abilities, chunk-strength, and frequency effects in implicit artificial grammar and incidental L2 learning: Replications of Reber, Walkenfeld, and Hernstadt (1991) and Knowlton and Sqquire (1996) and their relevance for SLA. Studies in Second Language Acquisition, 27, 235-268. doi: http://dx.doi.org/10.1017/S0272263105050126

Sasaki, M. (1996). Second language proficiency, foreign language aptitude and intelligence. New York: Lang.

Sheen, Y. (2007). The effect of focused written corrective feedback and language aptitude on ESL learners' acquisition of articles. TESOL Quarterly, 41, 255-283. doi: 10.1002/j.1545-7249.2007.tb00059.x

Sheen, Y., Wright, D., \& Moldawa, A. (2009). Differential effects of focused and unfocused written correction on the accurate use of grammatical forms by adult ESL learners. System, 37, 556-569. doi: 10.1016/j.system.2009.09.002

Skehan, P. (1998). A cognitive approach to language learning. Oxford: Oxford University Press.

Van Beuningen, C. G., De Jong, N., \& Kuiken, F. (2012). Evidence on the effectiveness of comprehensive error correction in second language writing. Language Learning, 62(1), 1-41. doi: 10.1111/j.1467-9922.2011.00674.x

Vatz, K. Tare, M., Jackson, S. \& Dought, C. (2013). Aptitude-treatment interaction studies in second language acquisition: Findings and methodology. In G. Granena \& M. Long (eds.), Sensitive Periods, Language Aptitude, and Ultimate L2 Attainment (pp. 273292). Amsterdam: John Benjamins.

Williams, J. (2012). The potential role(s) of writing in second language development. Journal of Second Language Writing, 21(4), 321-331. doi: http://dx.doi.org/10.1016/j.jslw.2012.09.007. 


\section{Tables}

Table 1. Criteria for scoring the past hypothetical conditional

\begin{tabular}{llll}
\hline Clause & Features & Components & Point \\
\hline $\begin{array}{lll}\text { if-clause } \\
\text { (maximum 2 }\end{array}$ & $\begin{array}{l}\text { the perfect aspect } \\
\text { the past tense }\end{array}$ & have (aux) + verb & 1.0 \\
points) & had & 0.5 \\
\hline main clause & the modal participle form & correct past participle & 0.5 \\
(maximum 3 & the perfect aspect & past modal & 1.0 \\
points) & the modal form & have (aux) + verb & 1.0 \\
& the past participle form & correct form of have (aux) & 0.5 \\
& & & 0.5 \\
\hline
\end{tabular}

Table 2: Descriptive statistics for accuracy scores for article and conditional

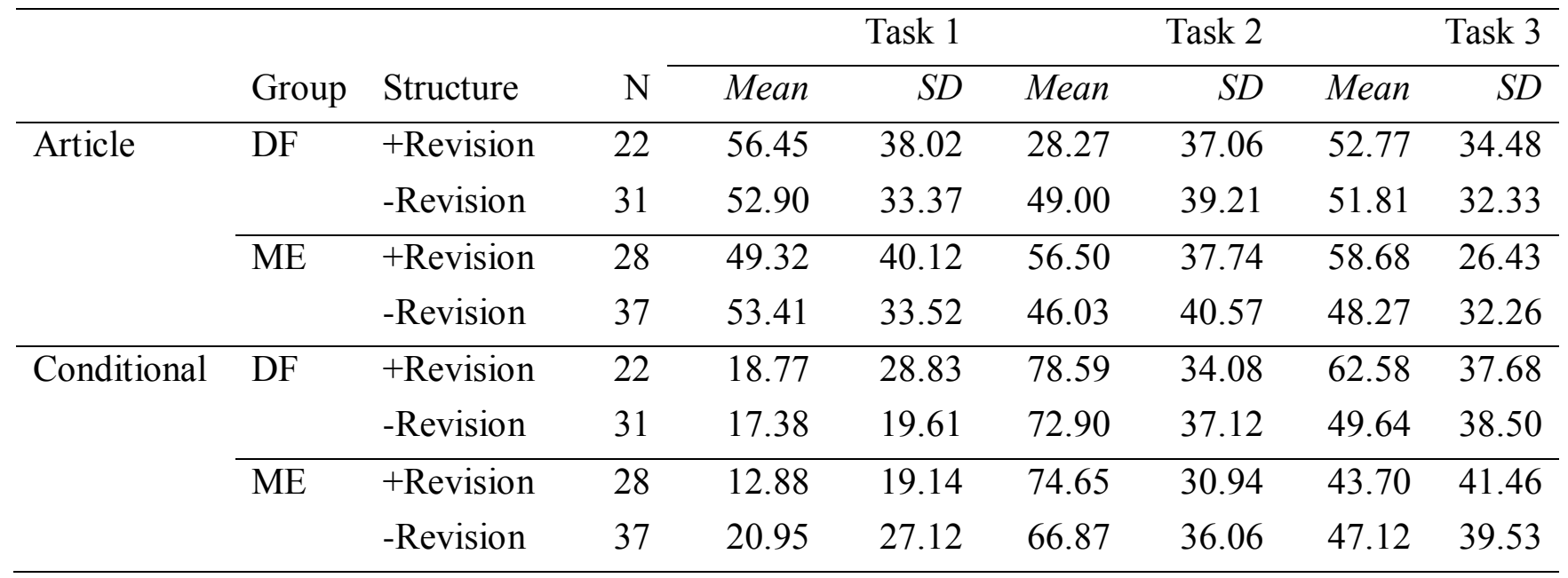


Table 3: Descriptive statistics for LABJ

\begin{tabular}{llrrr}
\hline & & & Labj \\
\cline { 4 - 5 } Group & Structure & $\mathrm{N}$ & Mean & $S D$ \\
\hline DF & +Revision & 22 & 14.23 & 1.11 \\
& -Revision & 31 & 14.19 & 1.14 \\
\hline ME & +Revision & 28 & 14.32 & .819 \\
& -Revision & 37 & 13.57 & 1.44 \\
\hline
\end{tabular}

Table 4: Partial Correlation for individual groups (1-tailed)

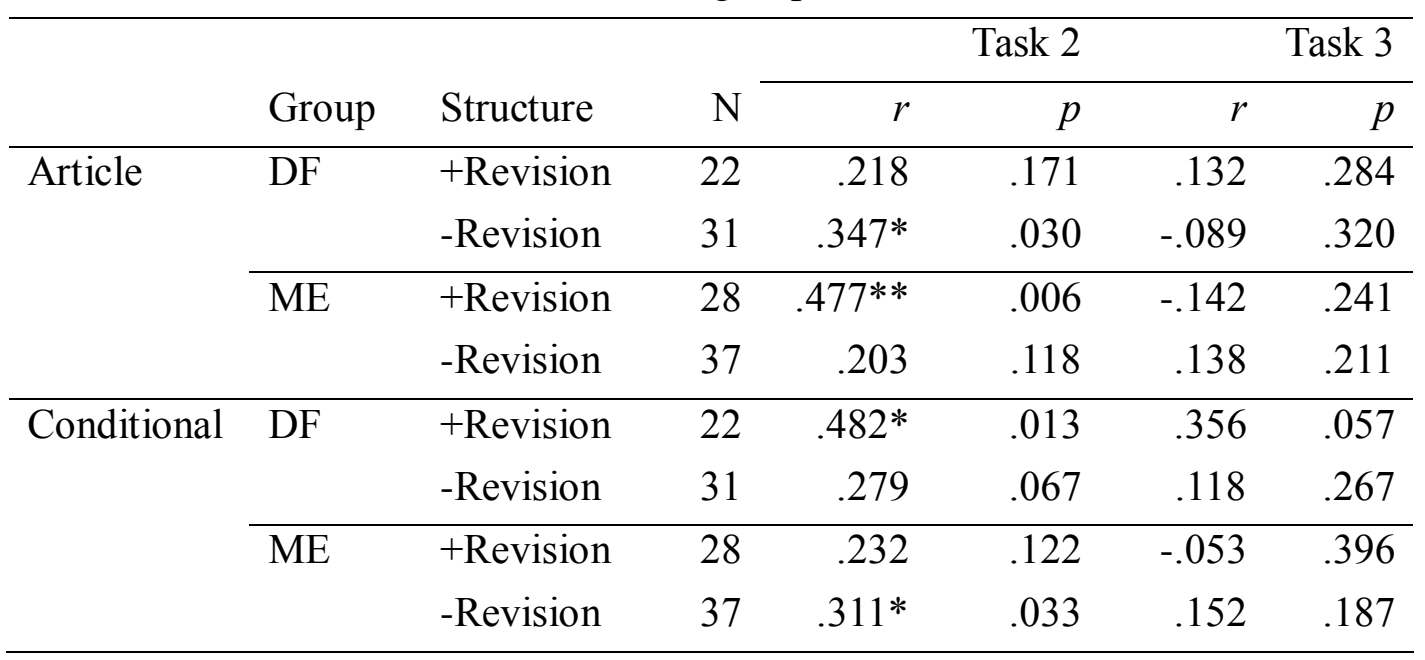

Table 5: Correlations for the two target structures in the different feedback conditions

\begin{tabular}{lllll}
\hline Type of CF & + --Revision & Required ability & Indefinite Article & $\begin{array}{l}\text { Hypothetical } \\
\text { conditional }\end{array}$ \\
\hline DF & - Revision & $\begin{array}{l}\text { Inducing the rule from } \\
\text { corrections provided }\end{array}$ & Moderate & Weak \\
& + Revision & $\begin{array}{l}\text { Using corrections } \\
\text { provided }\end{array}$ & Weak & $\begin{array}{l}\text { Moderate to } \\
\text { strong }\end{array}$ \\
\hline ME & - Revision & $\begin{array}{l}\text { Understanding the } \\
\text { rule explanation } \\
\text { Deductive application } \\
\text { of the rule }\end{array}$ & $\begin{array}{l}\text { Weak } \\
\text { strong }\end{array}$ & Moderate \\
\hline
\end{tabular}

